\title{
Robotic mitral valve surgery: Additive benefits without additive cost
}

\author{
Carol W. Chen, MD, and Pavan Atluri, MD
}

\footnotetext{
From the Division of Cardiovascular Surgery, Department of Surgery, University of Pennsylvania, Philadelphia, $\mathrm{Pa}$.

Disclosures: Authors have nothing to disclose with regard to commercial support.

Received for publication May 15, 2018; revisions received May 15, 2018; accepted for publication May 16, 2018; available ahead of print June 22, 2018.

Address for reprints: Pavan Atluri, MD, Division of Cardiovascular Surgery, Department of Surgery, University of Pennsylvania, Silverstein 6, 3400 Spruce St, Philadelphia, PA 19104 (E-mail: pavan.atluri@ uphs.upenn.edu). J Thorac Cardiovasc Surg 2018;156:1038-9

$0022-5223 / \$ 36.00$

Copyright (c) 2018 by The American Association for Thoracic Surgery

https://doi.org/10.1016/j.jtcvs.2018.05.052
}

Robotic approaches to cardiac surgery continue to gain interest from surgeons, patients, and referring physicians. The major focus of this technology has been to treat coronary and mitral valve pathology. As with any progressive technology, establishment of surgical durability and overall noninferiority in morbidity and mortality compared with the gold standard of care is vital. Additionally, in the current climate of health economics, the sustainability of new technology is often predicated on the demonstration of financial viability and responsible resource utilization.

Toward this goal, several groups have investigated the outcomes of robotic mitral valve surgery (RMVS), and have shown excellent repair rate and durability comparable with the gold-standard sternotomy approach. ${ }^{1,2}$ One of the first surgeons to perform a RMVS in the early 2000s, Dr Chitwood has since published a series of 540 patients who underwent robotic mitral valve repair in which all but $3(0.6 \%)$ patients had no to mild mitral regurgitation immediately postoperatively. ${ }^{3}$ Reoperation secondary to early technical failures occurred in only $4(0.7 \%)$ patients. In a series of 1000 patients who underwent RMVS reported by the Cleveland Clinic, $99.2 \%$ underwent valve repair. ${ }^{4}$ Of these patients, there was only 1 in-hospital death $(0.1 \%)$ and $1.4 \%$ rate of stroke. Similarly, Ramzy et al reported a single in-hospital mortality $(0.3 \%)$ in 300 patients from Cedars-Sinai Medical Center who underwent robotic mitral valve repair with $64.6 \%$ of patients in the most recent cohort having none to trace mitral regurgitation at 1 year. ${ }^{5}$

In this issue of The Journal of Thoracic and Cardiovascular Surgery, the report entitled, "Robotic mitral valve operations by experienced surgeons are cost-neutral and durable at 1 year," is on a progressive study in keeping with the technological advances in cardiac surgery. ${ }^{6}$ The authors, Coyan et al, should be commended for their efforts to systematically evaluate the merits of robotic technology as it becomes more widespread and integrated into cardiovascular programs worldwide. ${ }^{6}$

Coyan et $\mathrm{al}^{6}$ focus their study on comparing the cost of robotic mitral surgeries with those using traditional

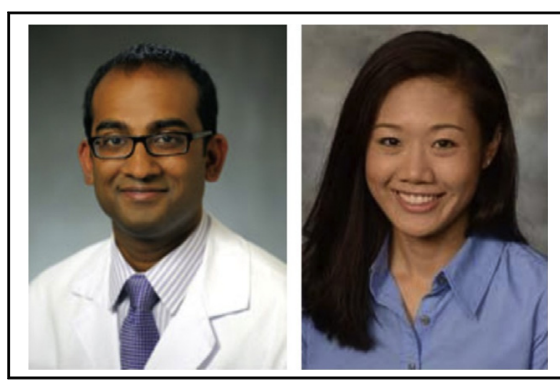

Pavan Atluri, MD (left), and Carol W. Chen, MD (right)

Central Message

Although the learning curve of robotic mitral valve surgery is steep, its increased use should be encouraged because of the benefits of rapid recovery, repair durability, and costeffectiveness.

See Article page 1040 .

sternotomy (SMVS). They use propensity score matching to derive separate robotic and sternotomy mitral valve surgery cohorts with similar baseline characteristics and comorbidities. From a population size of 328 patients who underwent mitral valve repair or replacement, approximately half in the RMVS and half in the SMVS cohorts, 182 patients were matched (91 in each treatment arm). Nearly half of the original cohort went unmatched, which alludes to the significant differences in patients selected for RMVS compared with SMVS. It would be interesting to note the costs of all patients who underwent RMVS in this study. If RMVS patients selected for the matched analysis had more comorbidities than the overall cohort of RMVS patients, it is likely that the total cost of RMVS is less than the $\$ 27,662$ as presented by Coyan et al. This lower cost could provide a basis to argue for the routine use of RMVS in all uncomplicated patients. Nonetheless, the authors successfully show durability and financial viability for robotic approaches to cardiac surgery. Although other centers including our own ${ }^{7}$ have shown the cost-effectiveness of minimally invasive mitral valve repair, the careful analysis of the additive cost associated with the robotic platform is especially important as surgeons consider acquisition of this equipment to their armamentarium.

Coyan et al should be congratulated for the excellent outcomes of their RMVS cohort and their meticulous analysis of the direct, semidirect, and indirect costs for their large series 
of patients. ${ }^{6}$ This study should provide further support to expand RMVS. As young surgeons seek to develop expertise in this complex technology, studies such as these should continue to provide a benchmark for excellent outcomes. Although the learning curve of RMVS is steep, the benefits of rapid recovery and repair durability should be appreciated.

\section{References}

1. Kesävuori R, Raivio P, Jokinen JJ, Sahlman A, Teittinen K, Vento A. Early experience with robotic mitral valve repair with intra-aortic occlusion. J Thorac Cardiovasc Surg. 2018;155:1463-71.

2. Suri RM, Dearani JA, Mihaljevic T, Chitwood WR Jr, Murphy DA, Trento A, et al. Mitral valve repair using robotic technology: safe, effective, and durable. J Thorac Cardiovasc Surg. 2016;151:1450-4.
3. Nifong LW, Rodriguez E, Chitwood WR Jr. 540 consecutive robotic mitral valve repairs including concomitant atrial fibrillation cryoablation. Ann Thorac Surg. 2012;94:38-42.

4. Gillinov AM, Mihaljevic T, Javadikasgari H, Suri RM, Mick SL, Navia JL, et al. Early results of robotically assisted mitral valve surgery: analysis of the first 1000 cases. J Thorac Cardiovasc Surg. 2018;155:82-91.e2.

5. Ramzy D, Trento A, Cheng W, De Robertis MA, Mirocha J, Ruzza A, et al. Three hundred robotic-assisted mitral valve repairs: the Cedars-Sinai experience. J Thorac Cardiovasc Surg. 2014;147:228-35.

6. Coyan G, Wei LM, Althouse A, Roberts HG, Schauble D, Murashita T, et al Robotic mitral valve operations by experienced surgeons are cost-neutral and durable at 1-year. J Thorac Cardiovasc Surg. 2018;156:1040-7.

7. Atluri P, Stetson R, Gaffey AC, Szeto WY, Acker MA, Hargrove WC. Minimally invasive mitral valve surgery is associated with equivalent cost and shorter hospital length of stay when compared to traditional sternotomy. J Thorac Cardiovasc Surg. 2016;151:385-8. 